\title{
MEMPERTAHANKAN KEBERADAAN KAMPUNG DI TENGAH-TENGAH KAWASAN MODERN JAKARTA
}

\author{
Sudarmawan Yuwono ${ }^{1}$ dan Sitti Wardiningsih ${ }^{2}$ \\ ${ }^{1}$ Universitas Bung Karno Jakarta \\ ${ }^{2}$ Arsitektur Lanskap Institut Sains dan Teknologi Nasional \\ sudarmawanyuwono@gmail.com, wardiningsih.sitti@gmail.com
}

\begin{abstract}
ABSTRAK. Orientasi pembangunan kota Jakarta adalah mewujudkan Jakarta sebagai kota global dan modern mampu berkompetisi dengan kota-kota dunia lainnya. Proses tersebut dilalui dengan optimalisasi lahan kota sebagai ruang produktif. Kondisi tersebut tidak dapat dihindari. Paradigma pembangunan kota berkelanjutan adalah mewujudkan masa depan berimbang antara kebutuhan generasi sekarang dan yang akan datang. Konsekuensinya proses pembangunan harus mampu memelihara nilai-nilai keadilan sosial budaya dan kemampuan menumbuhkan kehidupan bersama dalam kota. Penulisan penelitian ini diangkat dari sebuah cita-cita orang kampung untuk bertahan di tengah-tengah perkembangan sebuah kawasan paling mddern di Indonesia yaitu Segitiga Emas Kuningan. Suatu kondisi dualisme pemikiran pembangunan antara proses peningkatan kualitas fisik dan perekonomian kota serta proses pembangunan yang justru menghilangkan potensi sosial budaya masyarakat kehidupan kota. Adakah jalan keluar bagi permasalahan ini? Tulisan ini mengingatkan kewajiban para perencana dan perancang kota untuk mengintegrasikan nilai lokal-global dalam pembangunan kota. Tulisan ini merupakan gagasan dasar desain pengembangan kampung yang memiliki potensi sejarah dan budaya dalam rangka melestarikan nilai-nilai sejarah dan budaya kawasan global Kuningan.
\end{abstract}

Kata kunci: pembangunan kota berkelanjutan, lokal-global, kawasan modern, kampung

ABSTRACT. Orientation of the development of Jakarta is by creating Jakarta as global and modern city which could compete with other cities in the world. This process will get through by optimilizing urban land as a productive space. This condition for sure cannot be avoided. The paradigm of sustainable city development is by providing future which is balance between the need of present generation and future generation. The consequency of this development process should be able to maintain the values of socio-culture justification and the ability to create togetherness life within city. This paper has been conducted from the vission of kampung's community to survive in the middle of the development of modern district in Indonesia, particularly Segitiga Emas Kuningan. There is a dualism condition of development thinking and approach between a process of physical quality enhancement and economical condition of the city, as well as the process of development which is regarded will vanish the socio-culture potency within urban community. Is there any way out for this problems? This paper will remind the obligation of all parties including urban planners, architects and stakeholders to integrate all the global-local values in the process of city development. This paper is a basic idea of the design development of kampung which has a cultural and historical potency in the term to conserve and preserve the cultural and historical values of global area of Kuningan.

Keywords: sustainable development, global-local, modern area, kampung

\section{PENDAHULUAN}

Jakarta merupakan kota metropolitan terbesar atau "mega urban" di Indonesia. Bila pada masa kolonial, Batavia telah menjadi kota pelabuhan utama Hindia Belanda yang menghubungkan dengan kota kota dunia maka kondisi ini terus berkembang paska kemerdekaan, dengan penduduk berjumlah tidak kurang dari 12 juta jiwa maka Jakarta bukan saja hanya sebagai ibu kota negara, tetapi menjadi pusat perdagangan dan jasa, industri, serta pusat rekreasi dan harapan untuk bergantung hidup bagi seluruh masyarakat Indonesia. Kompleksitas permasalahan yang dihadapi Jakarta seperti politik, pendidikan, kejahatan serta budaya sebagai metropolitan bertumpang tindih dengan proses pembangunan kota.

Pasca reformasi proses globalisasi berkembang kembali menjadi semakin kuat dengan adanya kebijakan pemerintah mendukung berlangsungnya aliran modal asing dan iklim pasar bebas guna menggairahkan investasi dalam negeri. 
Pembangunan simbol-simbol global seperti mal/ pusat perbelanjaan modern, hipermarket hingga perkantoran modern dimulai kembali. Proses tersebut bercampur dengan berbagai kompleksitas persoalan yang harus dihadapi sebagai kota metropolitan seperti masalah urbanisasi, pertumbuhan penduduk kekurangan lapangan kerja dan kerawanan sosial.

Pembangunan kota adalah sarana pemerintah untuk mewujudkan amanat yang diberikan rakyat dalam suatu kebijakan dan tindakan untuk meningkatkan kesejahteraan masyarakat. Beberapa aspek hasil pembangunan dapat dinikmati seperti adanya peningkatan kualitas fisik infrastruktur dan perekonomian. Sepanjang jalan Jenderal Sudirman-Thamrin-Gatot Subroto-S Parman, fenomena pembangunan fisik telah dapat disaksikan. Demikian pula kehadiran mal-mal yang tersebar menunjukkan kegairahan gaya hidup dan semangat konsumerisme kota. Proses tersebut dalam kerangka pembangunan berkelanjutan diperlukan suatu keseimbangan untuk mengangkat potensi nilainilai lokal sebagai upaya mengembangkan konsep " glokalisasi ".

Persoalannya pembangunan properti telah menggantikan ruang-ruang kehidupan kebersamaan warga kota. Kota Jakarta semakin kehilangan kehidupan sosial keberagamannya digantikan kehidupan homogen perkotaan yang masif. Kondisi ini sangat tidak sehat karena membawa Jakarta menuju kebangkrutan kehidupan kota sebagaimana disinyalir oleh Trancik [1]. Perbedaannya persoalan kota-kota Amerika yang dilihat Trancik dihadapkan pada hilangnya sense of place, kenyamanan pejalan kaki, dan kehidupan yang manusiawi maka di Jakarta adalah hilangnya kesempatan warga untuk hidup bersama. Paper ini menyajikan potensi keberadaan kampung sebagai potensi lokal untuk dipertahankan dalam perkembangan kawasan modern.

\section{Nasib Kampung Dalam Pembangunan Properti}

Sejalan dengan program pembangunan fisik kota yang berdampak pada penggusuran kampung. Proyek penggusuran kampung digantikan dengan permukiman susun modern terjadi di kawasan perkampungan Kebon Kacang. Alasan yang diambil pemerintah adalah kondisi kampung yang ada ditengah tengah kota tidak memenuhi syarat lagi sebagai ruang permukiman yang sehat dan produktif.

Periode berikutnya pola pembangunan bersamaan dengan penggusuran kampung terus terjadi. Dikaitkan dengan proses transformasi global yang tengah terjadi maka proses ini paling tinggi intensitasnya dibandingkan kota-kota lain di Indonesia Jakarta telah lama menjadi metropolitan gerbang masuknya pengaruh-pengaruh global jauh sebelum menjadi gerbang dunia internasional negara Indonesia. Imbas transformasi global ini tidak hanya dalam wujud perkembangan berbagai fisik infrastruktur perekonomian modern seperti perkantoran, mal, apartemen namun juga terbentuknya kantung-kantung permukiman sederhana yang menggambarkan interaksi kehidupan kota dengan kawasan-kawasan yang masih tertinggal.

Pola politik pembangunan kota yang biasanya didukung oleh kekuatan-kekuatan pemerintah baik secara resmi atau tidak mendorong peningkatan pembangunan kota hingga masa keterpurukan pada krisis ekonomi tahun 19971998. Sekalipun dalam beberapa dekade terakhir ini banyak kampung yang digusur untuk pembangunan kawasan modern namun keberadaan kampung yang masih bertahan masih nampak dominan tetap berlangsung. Beberapa di antaranya benar-benar menjadi enclave di tengah-tengah perkembangan kawasan modern seperti dilihat pada kawasan Kebon Kacang, Kemayoran, Manggarai, kawasan antara Sudirman- Kuningan dan Mampang.

\section{Kondisi Kawasan Kuningan dan Lokasi}

Kawasan Kuningan merupakan bagian dari kecamatan Setiabudi Kotamadya Jakarta Selatan. Kawasan ini dalam kebijakan tata ruang kota Jakarta adalah representasi etalase kawasan internasional dengan adanya area pengembangan untuk kantor-kantor diplomatik, perusahaan multinasional dan hunian internasional.

Memasuki kawasan Kuningan ini melalui Bundaran Kuningan dari arah jalan Rasuna Said atau jalan Gatot Subroto, kita terasa berada di lingkungan kota-kota mancanegara yang maju. Gedung-gedung pencakar langit, jalur pejalan kaki, pertamanan yang indah, lingkungan yang menarik sebagaimana layaknya kawasan internasional. Sebagian besar kemajuan dan gemerlapan metropolitan Jakarta direpresentasikan di sini. 
Keberadaan hotel-hotel, apartemen dan pertokoan hipermarket serta berbagai obyek properti menandai semakin intensnya proses transformasi ekonomi sosial budaya global melalui proses arus investasi asing masuk di kota Jakarta. Namun demikian siapa pula menyangka di kampung yang tidak jauh dari kawasan diplomatik ini masih terdapat kehidupan kampung yang masih bertahan sejak ratusan tahun lalu.
Di kawasan pertumbuhan Kuningan rupanya masih terdapat hunian kampung yang memiliki perbedaan begitu menyolok ini dengan lingkungan sekitarnya, baik secara fisik rumahrumah yang ada, mata pencaharian warga, tradisi adat istiadat, kebiasaan dan hubungan kemasyarakatan.

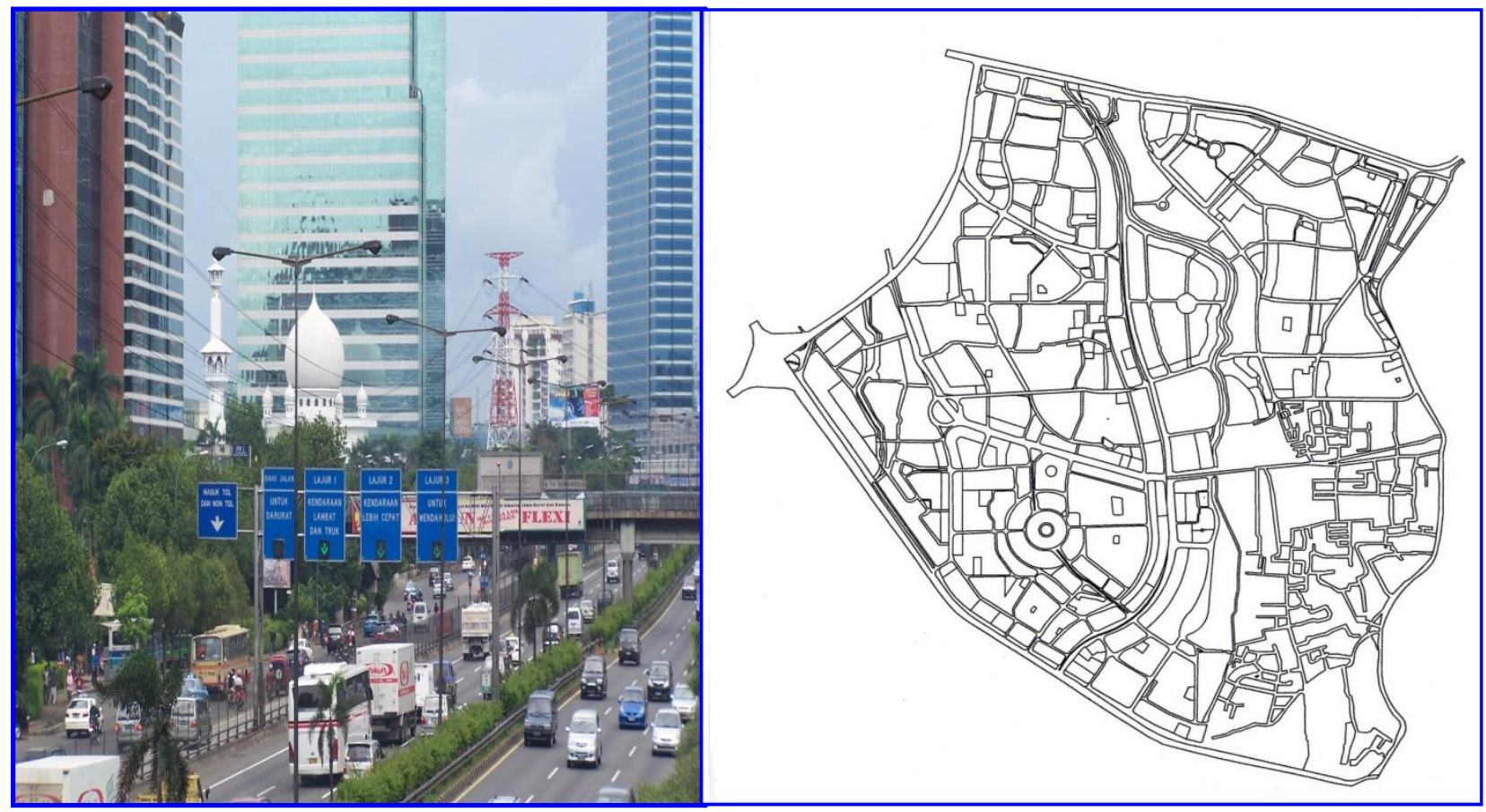

Gambar 2 Kawasan Segitiga Emas Kuningan

Sejak tahun 1970-an pembangunan kawasan Kuningan sangat pesat sejak ditetapkan sebagai kawasan internasional. Kawasan yang sebelumnya merupakan hanya kebun dan kampung ini menjadi kawasan perkantoran dan bisnis yang berskala internasional. Jakarta mempunyai banyak kawasan pertumbuhan seperti Bandar Kemayoran, Grogol, Blok M, namun keberadaannya tidak "se-emas" kawasan Kuningan.

Booming properti yang dimulai pada tahun 1990-an mendorong pembangunan kawasan Mega Kuningan sebagai kawasan yang memiliki nilai investasi. Pembangunan real estate di pusat kota bagi masyarakat golongan menengah ke atas tidak saja memiliki nilai fungsional tapi juga menjadi proses investasi. Regulasi pemerintah melalui Instruksi Gubernur DKI Jakarta No. 329 Tahun 1991 untuk ijin pembangunan apartemen, kondominium dan flat. Konsepnya mengacu pada konsep superblock yang meliputi perkantoran, hotel, apartemen, perbankan, supermarket dan restoran menjadi satu dalam satu blok kawasan.

Bila kita melihat pada periode $70-80$ sebagai periode persiapan maka periode $80-90$ sebagai periode pembebasan. Periode 90-96 sebagai periode booming pembangunan. Pada periode ini diwarnai banyak pameran properti hampir sepanjang tahun. Sedangkan periode 97-2000 periode masa kesuraman. Hal ini sangat cocok dengan kondisi dan perkembangan kawasan Mega Kuningan. Sementara kekuatan global yang ada memperlihatkan ketidakpekaan terhadap kondisi lokal bahkan dengan tradisi tradisi atau keunikan lokal.

Tahun 1990-1995 merupakan proses pemindahan warga Kuningan ke tempat lain secara besar-besaran. Paling banyak 
terkonsentrasi adalah warga yang berada di Pondok Ranggon sebanyak 24 keluarga yang mengusahakan budi daya sapi perah. Di Pondok Ranggon yang ditetapkan secara resmi sebagai lokasi budi daya sapi perah, petak-petak rumah tangga telah dipersiapkan. Warga yang pindah ke Pondok Ranggon ini sepenuhnya sudah lepas dari Kuningan. Kebijakan pemerintah melalui Instruksi Gubernur DKI Jakarta No. 329 Tahun 1991 untuk ijin pembangunan apartemen, kondomium dan flat mendorong proses konversi lahan di pusat kota sebagai lokasi pembangunan permukiman vertikal.

Pada periode ini istilah Segitiga Emas Kuningan diperkenalkan sebagai konsep kawasan ruang kota yang mengakomodasi berbagai kepentingan nasional maupun internasional. Pada tahun 1980-1995 an, perkembangan kawasan mulai diarahkan menjadi kawasan bisnis dan perdagangan internasional. Mulai terjadi pergeseran dalam perekonomian warga kampung. Sejak tahun 90-an, pemerintah DKI Jakarta mengeluarkan larangan beroperasinya aktivitas industri rumah tangga berupa pabrik pabrik batik dan aktivitas budi daya sapi perah karena kawasan ini telah ditetapkan menjadi kawasan permukiman dan perkantoran modern.

\section{POTENSI SEJARAH DAN SOSIAL BUDAYA KAMPUNG}

Dulu banyak mayoritas warga kampung Kuningan sebelum digusur pada tahun 90-an adalah pemilik usaha sapi perah. Sampai sekarang masih ada belasan warga yang masih mempertahankan usaha yang telah ditekuni dari orang tua mereka. Kondisi ini menunjukkan bahwa pada masa lalu daerah ini merupakan kawasan agraris. Ada istilah Karet Sawah mengingatkan adanya Sawah di sini, karet Pedurenan kawasan yang banyak pohon Duren). Karet Semanggi merupakan daerah rawa karena banyak tanaman " semanggi " yang biasa terdapat di rawa atau danau [2].

Keberadaan kampung Kuningan tidak dapat dipisahkan dari keberadaan mitos dan legenda Pangeran Kuningan. Adanya mesjid dan petilasan yang ditinggalkan Pangeran Kuningan menjadi penanda penting legenda tersebut. Dalam sejarah mesjid tua Heuken tidak menjelaskan adanya mesjid di kawasan ini hanya diceritakan ada mesjid di kawasan Mampang Prapatan yang bernama mesjid Istikmal [3]. Sebaliknya dari cerita warga ada beberapa mesjid yang tua yaitu Mesjid Al Mubarak atau dikenal dengan nama mesjid rusak karena diketahui kondisinya rusak hingga baru diperbaiki beberapa tahun belakangan. Mesjid ini dikenal dengan nama Mesjid Pangeran Kuningan. Makam Pangeran Kuningan yang diyakini oleh warga kampung sekarang telah menjadi lokasi bangunan megah, namun keberadaan mesjid tetap dilestarikan. Bahkan di gedung Telkom dibangun salah satu ruang yang disebut Ruang Pangeran Kuningan. Mesjid yang sangat megah ini berada di wilayah kelurahan Kuningan Barat.

Obyek sejarah paling penting di kawasan Mega Kuningan adalah makam dan mesjid Al Mughni. Makam Guru Mughni terletak di tengah tengah bundaran kawasan Mega Kuningan di depan Kantor kelurahan Kuningan Timur yang berada di lingkungan perumahan Perwira Tinggi TNI [4]. Kompleks makam yang dulunya terletak di tengah tengah permukiman ini kemudian di bangun mushala dan dipagar indah menjadi bagian arsitektur kawasan Mega Emas Kuningan. Pelestarian makam ini sangat dianjurkan untuk menjaga identitas serta sejarah kawasan serta monumen budaya kota Jakarta. Masjid besar di ujung jalan KH Guru Mughni dengan jalan Gatot Subroto yang sekarang dinamakan masjid Baitul Mughni adalah salah satu peninggalannya. Kemungkinan mesjid ini telah cukup lama dibangun pada masa hidup ulama besar tersebut. Sangat disayangkan mesjid ini sudah baru sama sekali tidak kelihatan lagi bekas bekas bangunan masjid lamanya.

Peninggalan bersejarah lain adalah Mesjid Baitul Mughni yang didirikan tahun 1910 (Riwayat Guru Mughni, 1990), kemudian dikembangkan menjadi mesjid modern lengkap dengan fasilitas pendidikan [5]. Mesjid ini menjadi salah satu wadah aktivitas warga sekitar termasuk tempat penyelenggaraan khaul KH Guru Mughni. Nilai sejarah lain adalah 2 (dua) makam tua. Pertama makam keluarga leluhur $\mathrm{KH}$ Guru Mughni seorang ulama besar sejaman $\mathrm{KH}$ Hasyim Asy'ari sekarang berada di tengah tengah kawasan namun dalam posisi aman.Dari kisah ini berarti identitas dan sejarah Jakarta tidak hanya ditandai keberadaan Kota Tua, Glodok, kawasan Jatinegara Kaum (makam Pangeran Jatinegara) kemudian Condet atau kampung Sawah di Srengseng Sawah namun juga bekas kampung Kuningan.

Di kawasan Kuningan yang menjadi artikulasi pertumbuhan ini denyut peradaban kota Jakarta dimulai sejak masa lalu. Keberadaan kampung Kuningan akan membentuk poros 
sejarah perkembangan kota Jakarta lama mulai sejak jaman Sunda Kelapa, Jayakarta, Jacatra, Batavia hingga menjadi Jakarta. Barangkali perlu dilakukan lagi penelusuran sejarah kampung ini secara arkeologi dan antropologi sehingga kebenaran sejarah yang berkembang di masyarakat dapat dipertanggungjawabkan secara ilmiah. Selanjutnya keberadaan kawasan ini dalam pembangunan kota Jakarta perlu ditandai agar jejak sejarah yang ada tidak hilang begitu saja.

Seandainya sejarah inipun sebatas mitos atau folkfore seperti halnya si Pitung atau Bang Jampang nampaknya juga perlu dipertimbangkan sebagai khasanah sosial budaya kota Jakarta. Kawasan yang berkembang sebagai kawasan modern ini dapat dipadukan dengan berbagai penanda sejarah yang berwujud artifak seperti taman makam, mesjid atau bahkan rumah tua.

Pertemuan antara unsur lokal tradisional dengan budaya modern yang kontras dapat menjadi nilai nilai arsitektur kawasan Kuningan. Kampung Kuningan terletak di tepi sungai Krukut yang berasal dari selatan Jakarta (ada kampung Krukut di Jakarta Selatan ini, di wilayah kota juga terdapat kampung Krukut). Hal ini menunjukkan bahwa kampung ini dulu dihubungkan dengan sungai Krukut [4].

Kampung Condet juga terletak di tepi Ciliwung. Kampung Kuningan masa lalu merupakan lintasan kota Batavia ke arah selatan dari Kota, Tenabang yang sejak dulu sebagai pasar, kampung Kuningan kemudian kampung Mampang hingga jauh ke selatan. Jalan lama yang ada adalah jalan $\mathrm{KH}$ Mas Mansyur sekarang kemudian jalan Prof Dr Satrio sekarang (dulu bernama jalan Karet Raya) memasuki jalan $\mathrm{KH}$ Guru Mughni (dulu merupakan jalan Karet Raya sebelum jalan Prof Dr Satrio yang sekarang bertemu dengan jalan HR Rasuna Said).

\section{NILAI NILAI SOSIAL BUDAYA KAWASAN}

Kampung Kuningan dikenal sebagai daerah penganut Islam yang taat, hal ini masih nampak bekas bekasnya dari banyak mesjid dan mushola yang tersebar. menjadi ciri masyarakat Betawi. Ciri lain ditandai banyaknya mushola dan masjid, Sebelum kemerdekaan, ada ulama terkenal yang disebut Guru Mughni yang dikenal sebagai tokoh masyarakat dan ulama yang banyak menguasai kepandaian ilmu agama. Semangat ini juga menjiwai warga kampung Kuningan untuk mengikuti jejak keluarga Guru Mughni dalam belajar agama. Aktivitas sosial warga yang terpenting adalah pada bidang sosial keagamaan dan aktivitas keagamaan seperti khaul dan pengajian pengajian. Tempat pengajian yang terpenting adalah mesjid Baitul Mughni dan mesjid Al Mubarak.

Setiap tahun diadakan acara khaul Guru Mughni dan Pangeran Kuningan. Dalam aktivitas khaul ini dihadiri oleh komunitas keagamaan di seluruh wilayah Jakarta Selatan kebetulan bertepatan dengan penyelenggaraan aktivitas pengajian akbar. Keberadaan khaul ini menyatukan kembali kesadaran sejarah warga asli kampung Kuningan sebagai warga yang berasal dari lingkungan yang satu. Warga Kuningan yang telah terpisah sejak pembangunan kawasan dan terpisah tempat tinggalnya sekarang menyatu dalam acara ini.

\section{TEMUAN: POTENSI KAWASAN}

Dari uraian di atas dapat dikemukakan bahwa kampung merupakan potensi kehidupan lokal kota yang menarik sekalipun seringkali lebih ditunjukkan adanya kekurangan secara fisik. Eksotisme kampung menjadi daya tarik kunjungan wisatawan dalam maupun manca negara. Pemerintah sendiri masih mempertahankan keberadaan kampung seperti Setu Babakan sebagai obyek wisata. Namun perlu juga dikemukakan bahwa keberadaan pola perkampungan di kota Jakarta merupakan gambaran umum yang biasanya dihubungkan dengan kepincangan dan karakteristik kota global negara sedang berkembang.

Sebagian tulisan menyebutkan bahwa $60 \%$ permukiman di Jakarta berwujud kampung dengan kata lain dibangun sendiri oleh warganya tanpa campur tangan pemerintah atau swasta. Sedangkan usaha-usaha pemerintah menyediakan tempat tinggal seperti rumah susun atau perumahan jauh sangat tertinggal. Alhasil keberadaan kampung-kampung pada masa modern ini masih menjadi pembentuk morfologi kota Jakarta yang sesungguhnya. Bahkan pandangan Kota Kampung Jakarta bukan lagi karena Jakarta dibentuk oleh kampung tapi karena pembentukannya tidak terencana atau cenderung alamiah mengikuti kemauan sendiri. Melalui konsep ini nilai-nilai lokal tidak terkecuali kampung dapat dipertahankan sebagai daya tarik kota bukan sebaliknya menjadi obyek penggusuran. 
Obyek potensi kawasan yang dapat dikembangkan dapat diuraikan sebagai berikut:

(1) Obyek makam dan mesjid sebagai potensi sejarah yang harus dipertahankan dan dikembangkan menjadi unsur kawasan.

(2) Obyek aktivitas budaya yang dikembangkan seperti warung/ cafe, penjualan cindera mata, dan jalan-jalan.

(3) Rumah Betawi yang harus dilestarikan sebagai penanda keberadaan komunitas dan kampung Betawi.

Hal tersebut merupakan potensi yang perlu dipertahankan guna mempertahankan nilainilai lokal kawasan. Disintegrasi fungsi kota: terjadi karena paradigma pertumbuhan cepat yang mengutamakan mekanisme pasar dengan sektor privat sebagai investor utama. Disintegrasi ditandai yaitu:

(1) kawasan tidak berfungsi dengan baik dengan seimbang serta saling mengisi,

(2) kawasan bukan lagi sebagai human settlement tapi obyek investasi atau wadah pertumbuhan ekonomi -akibatnya kota-kota ini berkembang tidak stabil, tidak aman dan kontraproduktif karena biaya sosial tinggi yang sering tersembunyikan dari angka angka statistik sehingga kian lama akan ditinggalkan investor.

Untuk itu diperlukan upaya menjaga koherensi (keutuhan) kota guna mencegah disintegrasi fungsi kota. Strategi mengatasi ada 2 (dua): Mengembangkan fungsi kota sebagai sentra di samping meningkatkan kota sebagai human settlement [6]. Kami membantah hal ini karena pendekatan ini masih tetap melihat kota sebagai pusat pertumbuhan dan kontradiksi dengan ide " desentralisasi ".

Istilah Little Betawi diambil dari ide seorang pemuda Kuningan yang melihat bahwa keberadaan kampung Kuningan perlu dipertahankan dalam konteks perkembangan modern kawasan Kuningan. Sebenarnya ide maupun tindakan warga kampung dalam mempertahankan kampung Kuningan telah banyak dilakukan antara lain dengan mengusahakan bertahannya makam Guru Mughni, mesjid Istiqomah dan mesjid Baitul Mughni. Dua obyek tersebut merupakan hasil suatu negosiasi antara warga, pengembang dan pemerintah. Pemikiran dalam penyusunan awal gagas konsep desain Little Betawi secara ringkas dapat diuraikan sebagai berikut:

(a) Kampung Kuningan memiliki potensi sebagai kawasan modern, (b) Kota Jakarta memerlukan kawasan tradisional lestari di samping keberadaan kawasan modern.

Dari 2 (dua) aspek tersebut maka keberadaan kampung melalui konsep Little Betawi tidak saja dipertahankan namun merupakan bagian terintegrasi dari kawasan Segitiga Emas Kuningan. Selanjutnya Little Betawi dapat dikembangkan menjadi konsep pembangunan kota berkelanjutan yang terdiri dari lingkungan konservasi dan pendukung kawasan Kuningan dalam bentuk ruang akomodasi, lingkungan wisata dan permukiman rakyat. Bentuk massa dikembangkan dari inspirasi tatanan arsitektur dalam permukiman Betawi yang terdiri dari rumah-rumah dengan latar belakang pekarangan dan kebun serta rumah-rumah petak sebagai ciri khas kampung di Jakarta. Bentuk arsitektur yang dikembangkan mengambil prototipe rumah arsitektur Betawi di kampung Kuningan yang masih dipertahankan. Lingkungan Little Betawi berinti pada preservasi dan pengutamaan penanda kawasan Mega Kuningan. Obyek preservasi adalah: Makam Guru Mughni, Mesjid Al Mughni, Langgar Al Makki, Rumah Betawi di RW 3, Unsur Hijau dan Pola Jalan [4]

Konsep MUD (Mixed Used Development) merupakan pengembangan kawasan yang mampu mengintegrasikan fungsi hunian, rekreasi, pendidikan, ruang terbuka-hijau, relijius dan konservasi. Dalam hal ini perlu dikembangkan 3 (tiga) unsur dalam kawasan yaitu yaitu unsur sosial ekonomi, unsur fisik dan unsur sosial budaya. Hal ini sesuai dengan konsep Carr [7] bahwa ada 3 (tiga) karakter ruang yang mampu mengintegrasikan kehidupan kota sebagai ruang publik yaitu:

(1) Responsif (responsive). Ruang yang melayani kebutuhan masyarakat terutama kenyamanan, kebutuhan berinteraksi dan sebagainya juga keseimbangan hidup rohani dan jasmani.

(2) Demokratis (democratic). Ruang yang melindungi hak-hak masyarakat, menerima semua kelompok serta ada tuntutan serta kepemilikan serta dapat belajar hidup bersama dalam masyarakat.

(3) Kaya makna (meaningfull). Ruang yang memiliki kesejarahan atau memori serta pengalaman yang berarti bagi masyarakat tertentu.

Adanya ruang publik sebagaimana dalam kawasan modern yang banyak kita saksikan sebagai "ruang privat" tidak banyak bermanfaat karena hanya memberikan manfaat secara "visual dan fisik" namun 
tercapainya suatu kualitas sosial ruang sama sekali tidak didapatkan.

\section{KESIMPULAN DAN REKOMENDASI}

Keberadaan unsur kampung dalam kawasan Kuningan Jakarta merupakan bagian nilai sejarah dan sosial budaya kota Jakarta. Keberadaan kawasan kampung tersebut perlu diintegrasikan dengan perkembangan kawasan Segitiga Emas Kuningan. Potensi sejarah dan sosial budaya tersebut adalah keberadaan kampung, mesjid dan makam yang merupakan gambaran fenomenal bertahannya tradisi berdampingan dengan modernitas kota Jakarta. Nilai-nilai tersebut dapat diangkat sebagai keunggulan arsitektur kawasan Mega Kuningan sebagai kawasan modern yan berakar pada nilai-nilai budaya kawasan.

Konsep Little Betawi merupakan revitalisasi kampung Betawi Kuningan untuk mempertahankan nilai-nilainya. Program ini hanya mengambil sebagian dari kampung yang memiliki potensi. Konsep desain adalah menampung pemberdayaan potensi dan aktivitas masyarakat, pelestarian rumah Betawi, masjid dan makam sehingga dapat menjadi obyek wisata kota. Semua aktivitas tersebut ditujukan untuk menunjang keberadaan Little Betawi tersebut. Kata kunci dari konsep Little Betawi ini adalah integrasi pelaku antara pemodal, masyarakat dan kebijakan pemerintah dalam memperhatikan potensi budaya kota Jakarta. Integrasi nilai ekonomi dan nilai sosial budaya sehingga dapat mempertahankan sebagian kampung Kuningan sebagai potensi lokal dalam kawasan global Kuningan. Sedangkan prinsip prinsip dasar yang harus dipertahankan adalah:

(1) Pelestarian sebagian kampung,

(2) Pengembangan potensi wisata,

(3) Pengembangan nilai nilai sejarah, sosial dan budaya kawasan dipadukan dengan perkembangan kawasan Mega Kuningan,

(4) Integrasi masyarakat dalam pengembangan kawasan baik dari aspek.

\section{REFERENSI}

[1] Trancik, Roger. (1986). Finding Lost Space : Theories of Urban Design. Van Nostrand. New York.

[2] Juwono, Sudarmawan dan $\mathrm{H}$ Wardie Asnawie. (2005). Mengungkap Sejarah
Kampung Kuningan. Diterbitkan pada kalangan sendiri.

[3] Heuken SJ, A. (2003). Mesiid mesiid Tua Di Jakarta. Penerbit Cipta Loka Caraka. Jakarta.

[4] Juwono, Sudarmawan. (2005). Prosiding Seminar Internasional Urban Conservation Universitas Trisakti dan Universitas Tokyo. In Explore of Urban Value in Historical Urban Kampung in Jakarta. Case of Kampung Kuningan.

[5] Team. 1990. Riwayat Hidup KH Guru Mughni. Kuningan Jakarta Selatan

[6] Santoso, Jo. (2006). Kota Tanpa Warga. Penerbit KPG dan Centropolis. Jakarta

[7] Carr, Stephen, Farcis Mark, Rivlin G.Leanne and Stone M. Andrew. (1992). Public Space, Environment and Behavior Series. Cambridge University Press. Cambridge. 
